\title{
ARTICLE
}

\section{Substantivism about truth}

\section{Gila Sher}

University of Califomia San Diego

\section{Correspondence}

Gila Sher, Department of Philosophy, 0119, University of Califomia San Diego, La Jolla, San Diego, CA 92093-0119.

Email: gsher@ucsd.edu

\begin{abstract}
Substantivism is a general philosophical methodology advocating a substantive approach to philosophical theorizing. In this article, I present an overview of this methodology with a special emphasis on the field of truth. I begin with a framework for understanding what is at stake in the substantivist-deflationist debate and describe the substantivist critique of deflationism. I then proceed to discuss contemporary substantivism as a positive methodology, present examples of recent substantivist theories of truth, delineate several principles of philosophical substantivism, and connect it to contemporary thought about the nature and methods of philosophy. Due to limitations of space, I am unable to discuss all the forms contem. porary substantivism has taken. But I try to give a clear sense of the central principles, challenges, and promise of this methodology.
\end{abstract}

\section{1 | INTRODUCTION}

Substantivism is a general philosophical methodology advocating a substantive approach to philosophical theorizing. "Substantive" is largely understood in the ordinary sense of the word, which includes such traits as "important," "significant," "deep," "interesting," "informative," "explanatory," "rigorous," "precise," "accurate," "thorough," and "subject to demanding norms of inquiry and justification." Substantivism encompasses both the subject-matter of philosophical theorizing and the theorizing itself. Substantivists claim that there are substantive philosophical subject-matters and that it is possible to theorize about such subject-matters in a substantive manner. But they treat the questions of what the subject-matters of philosophy are, which subject-matters are substantive, and how one could substantively theorize about them as open questions, indeed, as substantive questions that require a substantive inquiry.

Although contemporary substantivism started as a critique of deflationism, it is a positive methodology, standing on its own. Deflationism demonstrated the need to explicitly state, and defend, the principles of substantive theorizing in philosophy, and this, in turn, pointed to the need to critically examine the current principles, identify their shortcomings, and seek to improve or even replace them. It is this critical-constructive enterprise that is most characteristic of contemporary substantivism.

So far, the primary focus of contemporary substantivists has been on the philosophical subfield of truth. In this article, I will present an overview of substantivism with a special, though not exclusive, emphasis on this subfield. I will begin with a framework for understanding what is at stake in the substantivist-deflationist debate and describe the substantivist critique of deflationism from that perspective. I will then proceed to discuss contemporary substantivism as a positive methodology, present examples of recent substantivist theories, delineate several 
principles of philosophical substantivism, and connect it to contemporary thought about the nature and methods of philosophy. Due to limitations of space, I will not be able to discuss all the forms contemporary substantivism has taken. But I will try to give a clear sense of the central principles, challenges, and promise of this methodology.

\section{I HISTORICAL PERSPECTIVE}

Philosophy is known for its fluctuations between belief and disbelief in the viability of substantive philosophical theorizing: Aristotle versus the Greek skeptics, Hume versus Descartes, Popper versus Wittgenstein, and so on. Sometimes, such fluctuation involves skepticism toward one way of doing philosophy, confidence in another. Thus, Kant (1781/7) regarded the allegedly substantive metaphysics of his day as convoluted and ultimately empty, but instead of adopting a skeptical attitude toward substantive philosophy in general, he went on to develop what has become a paradigm of a substantive philosophical theory. Today, skepticism toward substantive theorizing in philosophy often takes the form of deflationism.

Two forebears of contemporary deflationism are Ramsey (1927) and the later Wittgenstein (1953/58/63). Ramsey advocated a conception of truth that renders it largely "redundant", and Wittgenstein advocated a general philosophical methodology-quietism-that counsels against all serious theorizing in philosophy. More recently, the shift from substantivism to deflationism can be seen in Hartry Field's work. ${ }^{1}$ In his influential critique of Tarski's (1933) theory of truth, the early Field (1972) argues that while Tarski's theory makes important contributions to mathematics and model theory, it fails as a general theory of truth. Field's argument is tied to a specific outlook of philosophy-physicalism-but from a substantivist perspective, his criticism is more general. One important way in which Tarski's theory fails, according to Field, is in its trivial treatment of atomic truth (reference and satisfaction). ${ }^{2}$ Tarski's account of atomic truth is an account by enumeration and as such does not satisfy the standards of substantiveness characteristic of fruitful branches of knowledge. Contrasting Tarski's definition with the scientific definition of valence, Field emphasizes that while the basic entries in Tarski's definition are defined by a list and as such are utterly trivial, the basic entries in the definition of valence are based on structural features of chemical elements, and this makes them highly informative. What the theorist of truth has to do, according to Field, is to develop a substantive account of truth (satisfaction and reference) for atomic sentences, and Field is especially drawn to Kripke's (1972/80) causal theory of reference as a blueprint for such a theory. In 1972, Field was optimistic about the prospects of a theory of this kind, but in the ensuing decades, he seems to have given up the project of constructing a substantive theory of truth, gradually moving toward deflationism. (For the latter Field's evolving views, see his 1986, 1994a, and 1994b works.)

\section{I THE SUBSTANTIVIST CRITIQUE OF DEFLATIONISM}

\section{1 | Central elements of deflationism}

Deflationists vary in what they take to be the central elements of deflationism. Here, however, we are interested in those elements that are especially significant from a substantivist perspective, and these are easier to identify. Five central elements of this kind-all found in Horwich (1990/8)-are as follows:

1. Frustration with past attempts to develop substantive theories of truth:

Deflationists are impatient with the idea of a substantive theory of truth. They say that traditionally, "a good answer" to the question "What is truth?" was thought to be "subtle, ... profound, and ... hard to find," there was an aura of "depth and difficulty which surround[ed] this concept," the "notion of truth" was thought to "pervade ... philosophical theorizing about the basic nature and norms of thought and action," and it was claimed that 
we need "insight into the underlying essence of truth." But "in inquiring into the nature of truth we have run up against the limits of analysis; and, indeed, it will be widely agreed that hardly any progress has been made towards achieving the insight we seem to need" (Horwich, 1990/8: 1).

2. Satisfaction with a trivial theory of truth:

Deflationists regard truth as a trivial subject-matter (concept, or property), ${ }^{3}$ one that does not require, or even allow, a serious philosophical investigation or a substantive theory. The "general thrust" of their approach is that "truth is entirely captured by ... trivialit[ies]," and they extol the fact that "nothing could be more mundane and less puzzling than the concept of truth" (ibid.: ix). They are satisfied with a trivial theory of truth, in the sense of a theory limited to trivial principles, and they regard the triviality of such a theory as a virtue rather than a liability.

3. Identification of the theory of truth with a single and simple definition schema:

[T]he deflationary point of view ... contains no more than what is expressed by uncontroversial instances of the equivalence schema,

(E) It is true that $p$ if and only if $p$. (Ibid.: 6)

The theory is exhausted by a collection of particular instances of this schema, or the related disquotational schema. ${ }^{4}$ It is limited to utterly trivial instances of this schema: "It is true that snow is white if and only if snow is white," "It is true that quarks really exist if and only if quarks really exist," "It is true that lying is bad if and only if lying is bad," and so on (based on ibid.: ix, 5). Even non-trivial renditions of these very instances, for example, "It is true that snow is white if and only if snow reflects light of all hues completely and diffusely" (based on Sher, 2016: 187), seem to be precluded.

4. Narrow conception of the role of truth in our cognitive life:

[T] he truth predicate exists solely for the sake of a certain logical need. On occasion we wish to adopt some attitude towards a proposition - for example, believing it, assuming it for the sake of argument, or desiring that it be the case - but find ourselves thwarted by ignorance of what exactly the proposition is. We might know it only as 'what Oscar thinks' or 'Einstein's principle'; perhaps it was expressed, but not clearly or loudly enough, or in a language we don't understand; or - and this is especially common in logical and philosophical contexts - we may wish to cover infinitely many propositions (in the course of generalizing) and simply can't have all of them in mind. In such situations the concept of truth is invaluable. For it enables the construction of another proposition, intimately related to the one we can't identify, which is perfectly appropriate as the alternative object of our attitude. (Horwich, 1990/8: 2-3)

\section{Bold adequacy claim:}

Referring to his own version of deflationism, "minimalism," Horwich says:

[O]ur thesis is that it is possible to explain all the facts involving truth on the basis of the minimal theory. (Ibid.: 6-7, my italics)

The entire conceptual and theoretical role of truth may be explained on this basis. (Ibid.: 5)

Substantivists reject all these elements: They are optimistic about the prospects of a substantive theory of truth, properly understood; they oppose both the idea that truth is trivial and the idea that its philosophical theory ought to be trivial; they conceive of a worthwhile theory of truth as a full-fledged theory rather than a single and simple definition or definition schema; they believe that truth has multiple significant tasks in our cognitive life and is not limited to a single, narrow, logical-linguistic task; and they argue that a deflationist theory of truth cannot explain all, or even most, of the things that a philosophical theory of truth has to explain. They are especially opposed to the claim that truth does not require, or even allow, serious philosophical investigation. 


\section{2 | Substantivist criticisms of deflationism}

Substantivist criticisms of deflationism vary in their degree of generality and specificity. Simplifying, I will describe a few types of "general" and "specific" criticisms.

\subsection{1 | General criticisms}

From a substantivist perspective, global deflationism-deflationism with respect to all philosophical theories-undermines philosophy's claim to be a serious branch of knowledge, and local deflationism does the same for particular subfields of philosophy. General substantivist criticisms of deflationism focus on its overall impoverishment of either philosophy as a whole or some particular field of philosophy. Two examples of such criticisms are as follows:

1. Lynch (2009) claims that truth deflationism leaves philosophy with an extremely limited stock of explanatory tools, including tools for explaining other philosophical subject-matters:

[D]eflationism come[s] with significant costs. ... [C]hief among them is that deflationism removes truth from our explanatory tooikit. ... If the deflationist is right, truth has no nature. Consequently, we cannot appeal to it to help explain other items of philosophical interest such as content. (bid.: 4-5)

Traditional theories are ... right to insist in the face of their deflationary critics that there is more to say about truth, and that what more there is to say can help us explain other items of interest. (lbid.: 5)

Deflationists of all varieties must remove truth from the philosopher's toolbox. They must convince us to give up truth as an explanatory notion, by which to explain meaning, or belief or the success of our actions. ... [1]f truth were part of an informative explanation of some other phenomenon of interest, we'd have good reason to think that there is more to say about it than the deflationist wishes to admit. (lbid.: 113)

2. Sher (2016) regards substantiveness as a universal "friction" requirement or constraint, applicable to theoretical knowledge qua knowledge, hence to all fields of knowledge:

A central friction requirement is substantiveness: the setting of high standards of discovery, explanation, justification, informativeness, depth, theoretical significance, rigor, systematicity, intellectual interest, and the like for all theories in our system of knowledge. (lbid.: 12, unitalicized)

She criticizes deflationism for neglecting this requirement.

Turning to truth, Sher argues that truth is too important and too complex to be adequately accounted for by a trivial theory. She contests the deflationist claim that the role of truth is limited to a narrow logical-linguistic task and claims that truth plays other, more central and substantive roles in our cognitive life. One such role is its role in knowledge. To highlight the fundamentality of this role, Sher's starting point is the "basic human cognitive (epistemic) situation" (2016: 162), a situation in which beings who are cognitively limited in some ways, endowed in others, seek to know the world they live in in its full complexity, in spite of their limitations, and know it not just practically but also theoretically. The combination of high epistemic aspirations and significant cognitive vulnerabilities increases the likelihood of error (failure), and therefore, a standard of correctness for this enterprise is essential. This fundamental role is far from trivial. Furthermore, a full understanding of this role, and of the way truth fulfills this role, involves understanding the relevant complexities of the human cognitive situation, and this requires both investigations and a theory that are far more complex and far more substantive than those sanctioned by deflationism.

\subsection{2 | Special criticisms}

Special criticisms of deflationism either challenge particular principles or claims or challenge general principles (claims) on specific grounds. Two examples of such criticisms are as follows: 
1. Wright (1992) challenges the claim that the equivalence/disquotational schema is a trivial, truly deflationary schema. Wright interprets the claim that the equivalence schema is a deflationary schema as saying that it does not treat truth as a substantial property. His argument against this claim proceeds as follows: According to deflationists, (E) says that to predicate truth on $p$ is merely to license the assertion of $p$. But this is not the case. While (E) does imply that truth has the same normative force as mere warranted assertibility, it does not imply that truth and warranted assertibility are the same (identical). Truth, as it appears in (E), has at least one property that warranted assertibility lacks: bivalence. This is reflected in their behavior vis-a-vis negation: It follows from the fact that $p$ is not true that $\sim p$ is true (bivalence), but it does not follow from the fact that $p$ is not warrantedly assertable that $\sim p$ is warrantedly assertable (non-bivalence). This shows that there is a substantial difference between truth and warranted assertibility, hence that truth has more content than deflationists attribute to it. Another way to put it, perhaps, is that bivalence is a substantial property; hence, if truth has this property, it is substantial rather than trivial.

2. Gupta (1993a, 1993b) challenges the sufficiency of a deflationist account of truth to do a variety of things that a theory of truth is required to do. For example, to account for laws involving truth (e.g., causal explanatory laws as in Putnam, 1978), we cannot do with a deflationist definition schema. The deflationist version of (E) provides no more than a collection of specific biconditionals and as such is limited to particular instances. But the account of laws requires genuine universal generalizations and, laws being counterfactual in scope, modal force sufficient to support counterfactual claims. But the deflationist collection of instances of the (E) schema is at most weakly equivalent to a universal generalization, and it lacks the requisite modal force. As such, it is incapable of accomplishing important tasks, let alone all the tasks, that a theory of truth is charged with accomplishing.

For additional examples of special criticisms, see, for example, David (1994), Shapiro (1998), and Ketland $(1999,2005)$.

The criticisms published so far, however, do not exhaust the likely criticisms of the deflationist approach. To bring just two examples,

1. Another argument against the deflationist claim that truth has only one task, a narrow logical-linguistic task, may focus on its logical form. This claim is a negative existential claim, and as such, it cannot be justified by showing that the narrow logical-linguistic task is $a$ task of truth. To show that a given task is a task of $X$ is not to show that it is the only task of $X$, but to the best of my knowledge, no published work on deflationism has shown the latter with respect to $X=$ truth. Furthermore, it is unlikely that deflationists will be able to justify this negative existential claim. Negative existential claims are often extremely difficult to establish, especially in fields like philosophy and in the context of "roles" (role of truth, role of language, role of morality, etc.).

2. Deflationism is susceptible to a "generalization ad absurdum" similar to Quine's (1935) "generalization" of logical conventionalism. Quine focused on the fact that logical conventionalism sets very low standards on logic. But if we allow very low standards in one field, Quine asked, why not in others? Why not in all? A similar criticism could be directed at deflationism, in light of the fact that it has been proposed for a number of philosophical theories (metaphysics, the theory of meaning, etc.) ${ }^{5}$ If we exempt some philosophical theories from high standards of substantiveness, why not others? And if some others, why not all? And if all philosophical theories, why not all theories in all fields of knowledge? But clearly, this would be absurd.

\subsection{Unwarranted assumptions and objective problems}

Substantivists seek to understand whether there are any objective difficulties with substantive theorizing in philosophy that might lead one, rightly or wrongly, to turn to deflationism. This question was taken up in Sher (1998, 2004, 2016) with respect to the theory of truth, and her answer is that a certain combination of circumstances might, indeed, encourage such a move. On the one hand, the concept or subject-matter of truth "is extraordinarily broad, 
complex and diversified, interwoven in different ways in different areas of our cognitive life, and applicable to sentences of different kinds (physical, psychological, mathematical, ethical, ..., concrete, abstract, ...) in different ways and for different reasons. As such it resists any attempt at a simple, sweeping characterization" (Sher, 1998: 142).

On the other hand, philosophers tend to assume that "if a substantive account of truth could be given at all, it could [would, should] be given by a single, and simple, definition or schema" (lbid: 141). This combination of circumstances might lie at the root of many philosophers' feeling that a substantive theory of truth is unfeasible and the only viable alternative is a deflationist theory.

But the assumption that the theory of truth must take the form of a single and simple definition or schema, Sher argues, is unwarranted. It is especially unjustified in light of the complexity and diversity of truth. The diversity problem does pose a serious challenge to the theory of truth, but this challenge is not unique to this theory or to philosophy. Sher compares the diversity problem of truth to the disunity problem in science, which is due to the breadth and diversity of its subject-matter-nature. But this problem is not insurmountable. The key to solving this problem, both in philosophy and in science, is summed up by Dyson's dictum that "every [theory] needs for its healthy growth a creative balance between unifiers and diversifiers" (Dyson, 1988: 47). Philosophical theories of broad and diverse subjectmatters such as truth, knowledge, objects, and meaning are best conceived as complex theories with principles varying in their degree of generality-some unifying, others diversifying (accounting for diversity), and most, as in science, substantive.

\section{I CONTEMPORARY SUBSTANTIVISM AS A POSITIVE METHODOLOGY}

As a positive conception of philosophy, contemporary substantivism says that philosophical subject-rnatters-truth, knowledge, objects, language, morals, and others-are in general substantive and that philosophical theories of those subject-matters ought to be deep, explanatory, and subject to demanding norms of inquiry and justification. Some philosophers use the term "inflationism" for what I mean here by "substantivism," but "inflationism," in my view, is less successful in capturing the main idea of substantivism. In a sense, "inflationism" captures the deflationist idea of substantivism. From a deflationist perspective, the main alternative to deflationism is an "inflated" theory of some philosophical subject-matter $X$, a theory in which the ratio of how much is said to the value of what is said is very large. But this is not the way substantivists regard their project. Substantivists are committed to doing what it takes to maximize the value of philosophical theories, regardless of the amount of inquiry this requires or the difficulties involved.

Contemporary substantivism, however, is very much a work in progress. And although most versions of substantivism exhibit certain commonalities, their focus varies. In the field of truth. some focus on the "property" and "nature" of truth (e.g., Edwards, 2013), some on the "theory" and "subject-matter" of truth (e.g., Sher, 2016). Some focus on the contributions of the theory of truth to other fields of philosophy le.g., Gupta, 1993a, 1993b; Lynch, 2009), some on the richness of truth itself (e.g., David, 1994).

\subsection{Substantivist conceptions of the theory of truth}

Three examples of recent substantivist theories of truth, or conceptions of such theories, are as follows:

\section{1 | Correspondence}

David (1994) delineates a substantivist conception of the theory of truth as a correspondence theory, with special emphasis on its substantive tasks. The main task of this theory, according to David, is to explain the relation between truths and relevant aspects of the world. This involves both the "ontology" and the "ideology" (in Quine's sense) of correspondence, and it requires solving, explaining away, or finding ways to avoid problems posed by various aspects of this relation (e.g., problems involving facts, such as those raised by Davidson, 1969). In addition, the theory has to "establish all of the fundamental laws that govern the notion of truth"-laws like "the negation of a truth is a 
falsehood'; 'the conjunction of a truth with its own negation is a necessary falsehood'; 'necessary truths can entail only necessary truths', and so on" (David, 1994: 9). More generally, the correspondence theory has to offer "a sufficiently rich system of fundamental principles about truth" (ibid: 10 ).

To this end, the theory may postulate theoretical entities (e.g., states of affairs or propositions), but it has to justify the need for such entities as well as spell out their identity conditions. Indeed, the theory has to satisfy a host of requirements-both general methodological requirements and requirements specific to a theory of truth: It "should not be circular to the point of becoming completely uninformative" (ibid.: 10), its "axioms ... should constitute intelligible generalizations" (ibid.), these generalizations should have a significant "modal force" (ibid.), the theory should account for all the data of truth, and others. The theory has to deal with the diversity of truth (e.g., the diversity of truth bearers), and it has to do so in a way that satisfies significant methodological requirements such as uniformity. The theory has to explain problematic cases, for example, cases in which some truth bearers appear to be neither true nor false or both true and false. It has to account for the connections between "truth" and other related notions, such as "meaning", and so forth. And while a definition of truth is just a small part of the theory, such a definition has to be stronger and more informative than the deflationist definition schema. The definition of truth should have the form of, or be generalizable to, a universal quantification, and its biconditionals "should have [appropriate] modal force", so it can "sustain certain types of subjunctives and counterfactuals" (ibid.: 8). Definitions of concepts invoked by the main definition may also be required, and so on.

In sum, a substantive correspondence theory of truth is, according to David, a full-fledged theory, going far beyond a single and simple definition schema, and satisfying a host of demanding methodological requirements met by substantive theories in all fields.

\section{I Pluralism of types of truth}

Wright $(1992,1999)$ and Lynch $(1998,2001,2004 \mathrm{a}, 2004 \mathrm{~b}, 2009)$ delineate a pluralist conception of a substantive theory of truth. The basic idea is that truth is governed not only by general principles but also by "specific" principles, which vary from field to field, and these principles are often substantive. The motivation for the specific principles arises from the "scope problem," which is essentially the diversity problem noted above. While causal correspondence may account for truth in physics, it cannot account for truth in mathematics, and while heavily human-dependent principles may explain truth in the legal domain, they are not suitable for the physical domain. Thus, truth in physics is likely based on correspondence principles, while truth in mathematics on other principles. Lynch directs us to Field (1972) and Devitt (1984/91) for a substantivist conception of causal correspondence in physics, and Wright (1999) provides an outline of a substantivist formalist-coherentist account of truth in pure arithmetic.

However, not all the principles of truth in Wright's and Lynch's theories are substantivist. For example, Wright's conception of truth in comic discourse is non-substantivist, and both Wright and Lynch conceive of the general principles of truth-those common to all fields of truth-as "platitudes." Whether platitudinous principles are necessarily trivial is an open question (see, e.g., Sher, 2005 and response by Lynch, 2005). From a substantivist perspective, we can determine whether a platitude $P$ is conceived by a theory $T$ as a self-standing trivial principle or as a caption for a substantive principle, by asking whether $T$ conceives of $P$ as requiring an in-depth investigation and account. Be that as it may, Wright's and Lynch's conception of most specific principles of truth is clearly substantivist. ${ }^{7}$

\section{I Pluralism within the bounds of correspondence}

Sher $(2004,2013,2015,2016)$ develops a conception of a theory of truth that limits pluralism to "forms" or "patterns" of correspondence and conceives of all principles of truth, specific as well as general, as substantive. Sher's starting point is the semi-Kantian question: Under what cognitive conditions does truth emerge in human life? Her answer is that truth requires three basic modes of cognition: the "immanent," "transcendent," and "normative" modes. The immanent mode is that of fixing one's cognitive gaze on the world (some aspect of the world), broadly understood. The transcendent mode is that of stepping beyond a given immanent thought and directing one's gaze both at it 
and at the world (in the case of truth, those aspects of the world which are the target of this thought). And the normative mode is that of setting standards for immanent thoughts vis-a-vis their targets in the world (in the case of truth, standards of correctness). This leads to the first general principle of truth, the "fundamental principle," which says that truth is a normative transcendent standard of correctness for immanent thoughts. The second general principle, correspondence, has to do with the relation between thoughts and their targets in the world. A third, "logicality", explains the role of logical structure in determining the truth value of sentences (thoughts and cognition). And there is room for other general principles as well. The substantivist character of these principles is reflected in the adequacy standards they are required to satisfy.

Although correspondence is a general principle of truth, to approach it in a substantivist manner involves, for Sher, critically examining traditional assumptions about its nature. Thus, she questions the assumption that correspondence takes a simple, straightforward form, that this form is that of copy, mirror, picture, or isomorphism, that it has the same form in all fields, and so on. These are open questions, calling for an open-minded investigation, and our answers to these questions have to take into account the complexity of those facets of the world that are targeted by a given thought (theory) and the cognitive routes available to us for reaching these facets. It is here that the moderately pluralist nature of the theory comes into expression. For an example of a special, nontraditional pattern of correspondence, Sher turns to mathematics. If we ask what facets of the world mathematical theories like arithmetic and set theory target, one possible answer is that they target formal features of objects (properties and relations), for example, cardinality features. This means that mathematical theories must be systematically connected to formal features (which are for the most part higher level). And this, in turn, suggests that reference and correspondence in first-order mathematics are indirect or "composite," in contrast to the traditional conception that commits mathematics to the existence of mathematical individuals.

\subsection{Substantivism as a general philosophical methodology}

Many philosophers have argued for a substantivist methodology for philosophy. For example, comparing philosophy ${ }^{8}$ to science, the early Field says that "we'd be crazy" to give up in philosophy "a methodology [of substantive theorizing] that has proved extremely fruitful in science" (Field, 1972: 363). Describing his outlook on philosophy, Dummett says:

The layman ... expects philosophers to answer deep questions of great import for an understanding of the world.... And the layman is quite right: if philosophy does not aim at answering such questions, it is worth nothing. (Dummett, 1976/91: 1)

This leads him to advocate a "constructive" approach to philosophy (lbid.). And setting the ground for his theory of justification, Goldman says:

The aim ... is to sketch a theory of justified belief. What I have in mind is an explanatory theory ... I want a set of substantive conditions ... I seek an explanatory theory, i.e., one that clarifies the underlying source of justificational status ... Its conditions must ... be appropriately deep or revelatory. ... A theory of justified belief of the kind I seek ... must be couched at a suitably deep... level. (Goldman, 1979: 1-2)

More recently, Williamson (2007) offers a normative-descriptive account of philosophy that is thoroughly substantivist. One of his main theses, the non-exceptionalism of philosophy, says that philosophy has significant commonalities with all other fields of knowledge, and many of these commonalities have to do with its substantivist character. Thus, philosophy, like other disciplines, has substantial rather than trivial subject-matters, its subjectmatters (e.g., necessity and possibility) are largely world- rather than language-oriented, and its aim is "starting from what we already know, ... to know more" (lbid.: 5). The knowledge philosophy seeks, like that sought by science and mathematics, is theoretical and systematic. The questions of philosophy, like their questions, have no obvious answers. Philosophy's main goal, like that of other branches of knowledge, is discovery. For example, the goal 
of metaphysics is "to discover what fundamental kinds of things there are and what properties and relations they have" (ibid.: 19). Philosophical methods, like the methods of mathematics and science, have their roots in ordinary knowledge-producing forms of cognition. These methods are not unique to philosophy. For example, logical reasoning is used in all fields of knowledge, abductive reasoning is used throughout science, counterfactual thinking is also characteristic of science, thought experiments are used in physics (Galileo and Einstein), armchair thinking is used in mathematics, and so on. To be considered a genuine discipline, philosophy, like all other disciplines, has to satisfy high standards of truth, explanation, evidence, accuracy, rigor, and others. Philosophical disputes, like disputes in other fields, are not verbal disputes. Evidence in philosophy, as in other sciences, is, and has to be, factual and knowledge based. Philosophy, like all other fields of knowledge, is subject to high standards and constraints; without these, it is not worth doing.

\section{5 | CONCLUDING REMARKS}

Although contemporary substantivism is very much a work in progress, its basic principles are quite clear:

S1. To be worthwhile, a field of knowledge has to be substantive.

S2. Theories, in all fields of knowledge, should be based on open-minded, serious investigations and be subjected to high standards of discovery, explanation, evidence, and justification.

S3. Philosophy falls squarely under $\mathrm{S1}$ and S2: Its subject-matters are (should be) substantive, its theories are (should be) based on in-depth investigations, and they are (should be) subject to high standards of explanation, justification, and others.

Substantivism's main task is to challenge philosophy and its practitioners, both theoretically and methodologically. Many philosophers would agree that, say, Kant's epistemic theory exemplified substantiveness in 18th-century philosophy. But many also believe, based on serious, open-minded investigations, that Kant's 18th-century theory had significant shortcomings. Philosophers are thus challenged to construct epistemic theories that are as substantive as Kant's yet avoid the shortcomings of Kant's theory and go beyond it both in discovery and in explanation. Similarly, today's philosophers are challenged to develop alternatives to traditional philosophical methodologies. For example, philosophers are challenged to develop an alternative to foundationalism, which, though a substantive methodology, was shown to be highly flawed. Rather than give up the foundational projects of philosophy altogether, philosophers are challenged to build better substantive foundational methodologies, ones that overcome the flaws of the traditional methodology. In the field of truth, critical investigations have pointed to serious inadequacies in traditional correspondence-overall naiveté and excessive simplicity, commitment to the existence of problematic entities, blindness to differences between diverse fields of application, and so on. Substantivists are challenged to rethink correspondence, question its traditional assumptions, and develop a new correspondence theory. If needed, philosophers are challenged to develop non-correspondence alternatives. It is in challenges of this kind, challenges that have partly been met but leave much work to be done, that, in my view, both the interest and promise of contemporary substantivism lie.

\section{ENDNOTES}

I Both Gupta and Martínez-Fernández (2005) and Sher (1998, 2004, 2016) emphasize Field's significance to the substantivism-deflationism debate.

2 "Atomic", in the context of Tarski's theory, means "lacking logical structure" or "devoid of logical constants".

3 Some go even further, saying it is not a genuine property or has no "nature" at all.

4 (D) " $p$ " is true if and only if $p$, where the letter " $p$ " stands for a declarative sentence (so that " $p$ "' in (D) stands for a quotational name of a declarative sentence). 
5 See, for example, Horwich (2004) and Thomasson (2014).

"Wright's examples of platitudes include "to assert is to present as true," "any truth-apt content has a significant negation which is likewise truth-apt," "to be true is to correspond to the facts," and "a statement may be justified without being true, and vice versa" (Wright, 1992: 34).

${ }^{7}$ For a general account of the pluralist approach to truth, one that is not primarily focused on its substantivist character, see Pedersen and Wright (2013).

"Field mentions "inguistics" rather than "philosophy," but what he has in mind is the discipline that contains Tarski's theory of truth, which is normally taken to be philosophy.

\section{WORKS CITED}

David, M. (1994). Correspondence and disquotation. Oxford: Oxford.

Davidson, D. (1969). True to the facts. Journal of Philosophy, 66, 748-764.

Devitt, M. (1984/91). Realism and truth. Oxford: Blackwell.

Dummett, M. (1976/91). The logical basis of metaphysics. Cambridge, Mass.: Harvard.

Dyson, F. (1988). Infinite in all directions. New York: Harper \& Row.

Edwards, D. (2013). Truth as a substantive property. Australasian Journal of Philosophy, 91, 279-294.

Field, H. (1972). Tarski's theory of truth. Journal of Philosophy, 69, 347-375.

Field, H. (1986). The deflationary conception of truth. In G. MacDonald, \& C. Wright (Eds.), Fact, science and morality. (pp. 55-117). Oxford: Blackwell.

Field, H. (1994a). Deflationist views of meaning and content. Mind, 103, 249-285.

Field, H. (1994b). Disquotational truth and factually defective discourse. Philosophical Review, 103, 405-452.

Goldman, A. (1979). What is justified belief? In G. S. Pappas (Ed.), Justification and knowledge. (pp. 1-23). Dordrecht: Reidel.

Gupta, A. (1993a). A critique of deflationism. Philosophical Topics, 21, 57-81.

Gupta, A. (1993b). Minimalism. Philosophical Perspectives, 7, 360-369.

Gupta, A., \& Martinez-Fernández, J. (2005). Field on the concept of truth-comment. Philosophical Studies, 124, 45-58.

Horwich, P. (1990/8). Truth. Oxford: Oxford.

Horwich, P. (2004). From a deflationary point of view. Oxford.

Kant, I. (1781/7). Critique of Pure Reason. London: Macmillan, 1929.

Ketland, J. (1999). Deflationism and Tarski's paradise. Mind, 108, 69-94.

Ketland, J. (2005). Deflationism and the Gödel phenomena: Reply to tennant. Mind, 114, 75-88.

Kripke, S. (1972/80). Naming and necessity. Cambridge: Harvard.

Lynch, M. (1998). Truth in context. Cambridge: MIT.

Lynch, M. (2001). A functionalist theory of truth. In The nature of truth. (pp. 723-749). Cambridge: MIT.

Lynch, M. (2004a). True to life. Cambridge: MIT.

Lynch, M. (2004b). Truth and multiple realizability. Australasian Journal of Philosophy, 82, 384-408.

Lynch, M. (2005). Replies to critics. Philosophical Books, 46, 311-342.

Lynch, M. (2009). Truth as one and many. Oxford: Oxford.

Pedersen, N. J. L. I., \& Wright, C. D. (2013). Pluralist theories of truth. In E. N. Zalta (Ed.), Stanford Encyclopedia of Philosophy (Spring 2016 Edition), URL=<http://plato.stanford.edu/archives/spr2016/entries/truth-pluralist/>.

Putnam, H. (1978). Meaning and the moral sciences. London: Routledge.

Quine, W. V. (1935). Truth by Convention. In The Ways of Paradox and Other Essays. (pp. 77-106). Cambridge, Mass: Harvard, 1976.

Ramsey, F. P. (1927). Facts and propositions. Aristotelian Society Supplementary Volume, 7. 153-170.

Shapiro, S. (1998). Proof and truth: Through thick and thin. Journal of Philosophy, 95, 493-521.

Sher, G. (1998). On the possibility of a substantive theory of truth. Synthese, 117, 133-172.

Sher, G. (2004). In search of a substantive theory of truth. Journal of Philosophy, 101, 5-36.

Sher, G. (2005). Functional pluralism. Philosophical Books, 46, 311-330.

Sher, G. (2013). Forms of correspondence: The intricate route from thought to reality. In N. Pedersen, \& C. D. Wright (Eds.), Truth \& pluralism: Current debates. (pp. 157-179). Oxford: Oxford. 
Sher, G. (2015). "Truth as composite correspondence". Unifying the philosophy of truth. Eds. T. Achourioti et al. Dordrecht: Springer. Pp. 191-210.

Sher, G. (2016). Epistemic friction: An essay on knowledge, truth, and logic. Oxford: Oxford.

Tarski, A. (1933). The concept of truth in formalized languages. In Logic, semantics, metamathematics. (pp. 152-278). Indianapolis: Hackett.

Thomasson, A. L. (2014). Deflationism in semantics and metaphysics. In A. Burgess, \& B. Sherman (Eds.), Metasemantics: New essays on the foundations of meaning. (pp. 185-213). Oxford: Oxford.

Williamson, T. (2007). The philosophy of philosophy. Malden, Mass.: Blackwell.

Wittgenstein, L. (1953/58/63). Philosophical investigations. Oxford: Basil Blackwell.

Wright, C. (1992). Truth and objectivity. Cambridge: Harvard.

Wright, C. (1999). Truth: A traditional debate reviewed. In S. Blackburn, \& K. Simmons (Eds.), Truth. (pp. 203-238). Oxford: Oxford.

How to cite this article: Sher, G. (2016), Substantivism about truth, Philosophy Compass, 11, 818-828. doi: 10.1111/phc3.12378

\section{AUTHOR BIOGRAPHY}

Gila Sher received her BA from the Hebrew University of Jerusalem and her PhD from Columbia University (1989). She is a philosophy professor at the University of California San Diego. Her research centers on foundational issues in epistemology, the theory of truth, and the philosophy of logic. She advocates a substantivist approach to philosophy and is interested in new perspectives on classical philosophical problems. Her book, The Bounds of Logic (MIT, 1991), investigates the nature of logic through the nature of logical constants. Her book. Epistemic Friction: An Essay on Knowledge, Truth, and Logic (Oxford, 2016), offers an integrated account of three central fields of philosophy. 